\title{
Chemical Behaviour of Dissolved Oxygen during Deoxidation with Silicon*
}

\author{
By Yoshio Miyashita**
}

\begin{abstract}
Synopsis
For the determination of the content of oxygen dissolved in molten steel containing oxide inclusions, $\mathrm{SiO}_{2}$, the radioactive tracer method has been applied in the current work. The principle aspect of this technique is to distinguish the primary deoxidation products from the oxides formed during the period of cooling and freezing by the addition of radioactive silicon just before cooling. Since the exchange of silicon does not take place between metal and oxides, the oxides formed during the period of cooling and freezing are only radioactive, but not the primary deoxidation products. Assuming that the most of dissolved oxygen is associated with silicon due to the reason that the affinity between silicon and oxygen is more stronger than the others, the content of oxygen dissolved may be estimated from the radioactivity of $\mathrm{SiO}_{2}$ extracted from the sample. By this method, the process of silicon deoxidation may be more clearly understood.
\end{abstract}

\section{Introduction}

Many valuable informations are available on the problems at end point, or in the equilibrium state of the deoxidation reaction. On the contrary, only a few investigations has been made on the rate of the reactions. Since there is no detail investigation on the rate of reactions, the mechanism of a reaction, the nucleation and the growth of oxide particles, and the floatation of the oxides have not been clearly understood. For the kinetic study of deoxidation, the oxygen dissolved should be distinguished from the oxygen in the form of oxides in melt. According to the method applied by the others, total amount of oxygen in the sample or oxygen in the form of oxides in solidified iron is only determined, but not the amount of the dissolved oxygen in the process of deoxidation. The latter value has been estimated indirectly by some authors from the amount of deoxidizing elements using the equilibrium relation.

Recently, the activity of oxygen has been determined by the measurement of electromotive force. ${ }^{1-5}$ ) However, the application of this method is restricted to certain cases. Thus, there seems to be no suitable method for the direct determination of the amount of oxygen dissolved in the process of deoxidation.

To determine directly the content of oxygen dissolved in the melt which is containing the oxide inclusions in it, applicability of the radioactive tracer method has been investigated in this work, especially on the change in the content of oxygen dissolved during the process of deoxidation with silicon.

\section{Method Used for the Determination of the Dissolved Oxygen Content}

\section{Principle}

The principle of this method is based on the fact that the primary deoxidation products and the oxides formed during the period of cooling and freezing can be distinguished if the radioactive silicon, ${ }^{31} \mathrm{Si}$, is added to the melt just before cooling starts. In this case, the oxides formed during the period of cooling and freezing are radioactive, while the primary deoxidation products are not. The content of oxygen dissolved can, therefore, be determined by measuring the radioactivity of $\mathrm{SiO}_{2}$ extracted from the samples, if the following consideration is made, that is, the most of the dissolved oxygen associates with silicon, forming radioactive oxides, due to the strong affinity between them as compared with the others.

\section{Assumptions}

The technique proposed in the current study is only applicable when the following assumptions are well satisfied :

(1) Behaviour of the radioactive silicon, ${ }^{31} \mathrm{Si}$, should entirely be equal to the ordinary inactive silicon, such as ${ }^{28} \mathrm{Si},{ }^{29} \mathrm{Si}$ and ${ }^{30} \mathrm{Si}$.

(2) Added ${ }^{31} \mathrm{Si}$ should be distributed uniformly in the melt within a short period of time.

(3) No replacement or exchange of silicon atoms takes place between metal and oxides.

(4) The amount of radioactive $\mathrm{SiO}_{2}$ floated up to the time of sampling is negligibly small.

(5) Not only the primary but also the secondary deoxidation products formed during the period of cooling and freezing are all in the form of pure $\mathrm{SiO}_{2}$.

(6) Deoxidized product $\mathrm{SiO}_{2}$ can be fully extracted from solid iron sample.

\section{Method}

In Fig. 1, curve-A shows the change of the content of dissolved oxygen with the time after the addition of silicon, $m_{1} \%$, while curve-B shows the relation between the content of dissolved oxygen and the time in case that $m_{1}$ and $m_{2} \%$ silicon is added at the times, $t_{1}$ and $t_{2}$, respectively.

In order to determine the content of dissolved oxygen at the time $t_{2}$, two experiments are made in the sequence as shown in Table 1, and the samples are all taken out from the melt at the time $t_{3}$.

The following symbols are used in the current investigation.

* Si: Silicon containing ${ }^{31} \mathrm{Si}$.

$a_{\mathrm{A}}$ : radioactivity of $1 \mathrm{~g}$ of $* \mathrm{Si}$ used in experiment-A

$a_{\mathrm{B}}$ : radioactivity of $1 \mathrm{~g}$ of $* \mathrm{Si}$ used in experiment-B.

* Presented at the 67th ISIJ Meeting, April 1964, in Tokyo. Originally published in Tetsu-to-Hagané (Journal, Iron \& Steel Institute, Japan), 52 (1966), 1049 in Japanese. English version received September 12, 1966.

** Technical Research Institute, Nippon Kokan K.K., Minami-Wataridacho, Kawasaki. 


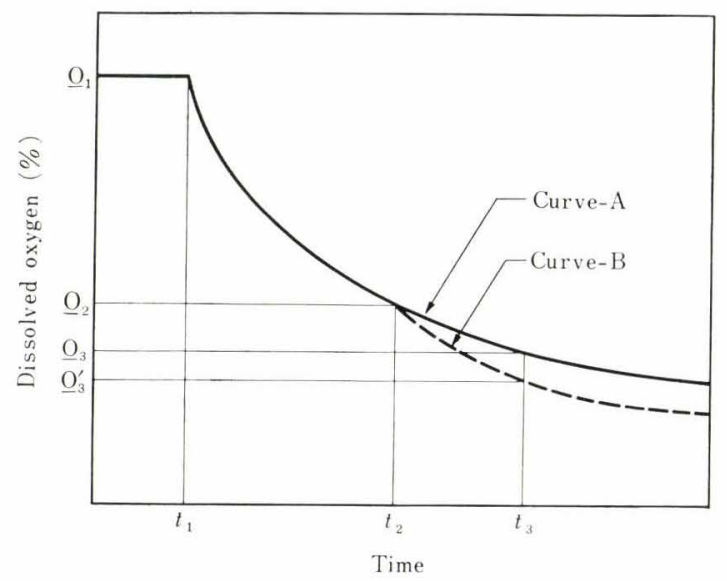

Fig. 1. Changes in the contents of dissolved oxygen after the additions of silicon

Table 1. Sequence of silicon additions

\begin{tabular}{c|c|c}
\hline Time & $t_{1}$ & $t_{2}$ \\
\hline Experiment- $A$ & $\begin{array}{c}\text { Active silicon } \\
{\left[m_{1} \%\right]}\end{array}$ & - \\
\hline Experiment $-B$ & $\begin{array}{c}\text { Inactive silicon } \\
{\left[m_{1} \%\right]}\end{array}$ & $\begin{array}{c}\text { Active silicon } \\
{\left[m_{2} \%\right]}\end{array}$ \\
\hline
\end{tabular}

$a^{\prime}{ }_{\mathrm{B}}$ : radioactivity of $1 \mathrm{~g}$ of metallic silicon in the melt in experiment-B just after time $t_{2}$.

$N_{\mathrm{A}}$ : radioactivity of $\mathrm{SiO}_{2}$ extracted from $1 \mathrm{~g}$ of the sample in experiment-A.

$\mathcal{N}_{\mathrm{B}}$ : radioactivity of $\mathrm{SiO}_{2}$ extracted from $1 \mathrm{~g}$ of the sample in experiment-B.

$I_{\mathrm{A}}$ : count rate of $\mathrm{SiO}_{2}$ extracted from $1 \mathrm{~g}$ of the sample in experiment-A.

$I_{\mathrm{B}}:$ count rate of $\mathrm{SiO}_{2}$ extracted from $1 \mathrm{~g}$ of the sample in experiment-B.

$\mathrm{O}_{\text {od }}\left(t_{n}\right)$ : Oxygen content $(\%)$ in the form of $\mathrm{SiO}_{2}$ in melt at time $t_{n}$.

The radioactivity of $\mathrm{SiO}_{2}$ extracted from $1 \mathrm{~g}$ of the sample which is taken out at the time $t_{3}$ is given as follows:

$$
\begin{aligned}
& \mathcal{N}_{\mathrm{A}}=\frac{1}{100} \frac{28.09}{32}\left\{\mathrm{O}_{\text {od }}\left(t_{3}\right)+\underline{\mathrm{O}}_{3}\right\} a_{\mathrm{A}} \\
& \mathcal{N}_{\mathrm{B}}=\frac{1}{100} \frac{28.09}{32} \underline{\mathrm{O}}_{2} a_{\mathrm{B}}^{\prime}
\end{aligned}
$$

In Eq. (2), $a_{\mathrm{B}}^{\prime}$ is

$$
a_{\mathrm{B}}^{\prime}=a_{\mathrm{B}} \frac{m_{2}}{m_{1}-(28.09 / 32)\left(\underline{\mathrm{O}}_{1}-\underline{\mathrm{O}}_{2}\right)+m_{2}}
$$

Denominator of the right hand side of Eq.(3) shows the content of metallic silicon in weight percent when * Si added at the time $t_{2}$ is entirely dissolved. Since all of the measurements were carried out in the same procedure, it is possible to assume that the count rates are proportional to the radioactivity. Therefore, it can be expressed as follows:

$$
\frac{I_{\mathrm{B}}}{I_{\mathrm{A}}}=\frac{\mathcal{N}_{\mathrm{B}}}{\mathcal{N}_{\mathrm{A}}}=\frac{a_{\mathrm{B}}^{\prime}}{a_{\mathrm{A}}} \frac{\underline{\mathrm{O}}_{2}}{\mathrm{O}_{\mathrm{od}}\left(t_{3}\right)+\underline{\mathrm{O}}_{3}}
$$

From Eqs. (3) and (4)

$$
\frac{I_{\mathrm{B}}}{I_{\mathrm{A}}}=\frac{a_{\mathrm{B}}}{a_{\mathrm{A}}} \frac{m_{2}}{m_{1}-(28.09 / 32)\left(\underline{\mathrm{O}}_{1}-\underline{\mathrm{O}}_{2}\right)+m_{2}} \frac{\underline{\mathrm{O}}_{2}}{\mathrm{O}_{\mathrm{od}}\left(t_{3}\right)+\underline{\mathrm{O}}_{3}} \ldots
$$

If the content of oxygen in the form of $\mathrm{SiO}_{2}$ is denoted as $\mathrm{O}_{\text {tot }}$, it is given as

$$
\mathrm{O}_{\text {tot }}\left(t_{3}\right)=\mathrm{O}_{\text {od }}\left(t_{3}\right)+\underline{\mathrm{O}}_{3}
$$

and, therefore, Eq. (5) can be rewritten as follows :

$$
\frac{I_{\mathrm{B}}}{I_{\mathrm{A}}}=\frac{a_{\mathrm{B}}}{a_{\mathrm{A}}} \frac{m_{2}}{m_{1}-(28.09 / 32)\left(\underline{\mathrm{O}}_{1}-\underline{\mathrm{O}}_{2}\right)+m_{2}} \frac{\underline{\mathrm{O}}_{2}}{\mathrm{O}_{\mathrm{tot}}\left(t_{3}\right)}
$$

In Eq. (6), $\mathrm{O}_{\text {tot }}\left(t_{3}\right)$ can be obtained from the content of $\mathrm{SiO}_{2}$. On the other hand, $I_{A}$ and $I_{\mathrm{B}}$ are determined from the measurement of radioactivity of $\mathrm{SiO}_{2}$ extracted. Since the values of $a_{\mathrm{A}}, a_{\mathrm{B}}, m_{1}, m_{2}$ and $\underline{\mathrm{O}}_{1}$ are known, the content of dissolved oxygen $\underline{\mathrm{O}}_{2}$ can easily be calculated from Eq. (6). Instead of the absolute values of $a_{\mathrm{A}}$ and $a_{\mathrm{B}}$, relative values can be used.

For the convenience, Eq. (6) may be rewritten as follows :

$$
\underline{\mathrm{O}}_{2}=\frac{a_{\mathrm{A}}}{a_{\mathrm{B}}} \frac{I_{\mathrm{B}}}{I_{\mathrm{A}}} \mathrm{O}_{\mathrm{tot}}\left(t_{3}\right) \frac{m_{1}+m_{2}-(28.09 / 32)\left(\underline{\mathrm{O}}_{1}-\underline{\mathrm{O}}_{2}\right)}{m_{2}}
$$

Since the value of $\underline{\mathrm{O}}_{2}$ is negligibly small as compared with the values of $m_{1}, m_{2}$ and $\underline{\mathrm{O}}_{1}$ for the most of cases, Eq. (7) may be simplified:

$$
\underline{\mathrm{O}}_{2}=\frac{a_{\mathrm{A}}}{a_{\mathrm{B}}} \frac{I_{\mathrm{B}}}{I_{\mathrm{A}}} \mathrm{O}_{\text {tot }}\left(t_{3}\right) \frac{m_{1}+m_{2}-(28.09 / 32) \underline{\mathrm{O}}_{1}}{m_{2}}
$$

The change of the content of dissolved oxygen after the addition of silicon can be known by several runs of experiment-B which are carried out under the same conditions except for the time of radioactive silicon addition $\left(t_{2}\right)$. Values of $a_{\mathrm{A}}, I_{\mathrm{A}}$ and $\mathrm{O}_{\text {tot }}$ obtained from experiment-A are used for all runs of experimentB. In experiment-A, $m_{1}, \underline{\mathrm{O}}_{1}$, and the time $t_{3}$ can be chosen independently with the conditions of experiment-B. Radioactive silicon, ${ }^{31} \mathrm{Si}$, having the halflife of $2.62 \mathrm{hr}$ can easily be produced by activating ordinary silicon in a nuclear reactor.

The radioactive tracer method used in the present work may also be used for the study of deoxidation processes in which one of other elements is used as a deoxidizer. ${ }^{6}$ ) In cases where the deoxidation products are composed of the oxides of the added deoxidizer itself, the present method can be applied as it is. However, some modification may be made if the deoxidation products are composed of the oxides of several species. ${ }^{6)}$ In addition, the present method may also be used for the determination of equilibrium constants, particularly when the methods commonly used fail due to the strong affinity between deoxidizer and oxygen.

\section{Experimental Procedure}

\section{Melting}

In each run, $1.2 \mathrm{~kg}$ of electrolytic iron $(\mathrm{C}=0.001$; $\mathrm{Mn}=0.002 ; \mathrm{Al}, \mathrm{Si}<0.001 \%)$ was melted in a magnesia crucible (i.d. $=5.3 \mathrm{~cm}$ ) with an induction furnace of $400 \mathrm{kc}$ and $15 \mathrm{~kW}$. To prevent further oxidation of the melt, argon gas was used during the experiment. Temperature of the melt was meas- 
ured with a Pt-13\%Rh.Pt thermocouple and maintained at $1600^{\circ} \mathrm{C}$ within the accuracy of $\pm 5^{\circ} \mathrm{C}$. For the initial deoxidation, $0.5 \%$ of silicon $(\mathrm{Si}=99.08$; $\mathrm{Fe}=0.19 ; \mathrm{Ca}=0.092 ; \mathrm{Al}=0.032 ; \mathrm{C}=0.012 ; \mathrm{Mn}=$ $0.009 ; \mathrm{P}=0.007 \%$ ) was added at the time $t_{1}$, and then, radioactive silicon of $0.1 \%$ was added to the melt at the time $t_{2}$ for the experiment-B.

\section{Activation of Silicon}

In order to produce radioactive silicon, ordinary silicon was irradiated for $2-3 \mathrm{hr}$ in a nuclear reactor having thermal neutron flux of $3 \times 10^{11} \mathrm{n} / \mathrm{cm}^{2} \cdot \mathrm{sec}$. Since the target material contains a small amount of impurities, the irradiated product is not radiochemically pure. The amounts of radioisotopes produced by irradiating $1 \mathrm{~g}$ of silicon for $1 \mathrm{hr}$ with thermal neutron flux of $1.0 \times 10^{11} \mathrm{n} / \mathrm{cm}^{2} \cdot \mathrm{sec}$ were calculated and are listed in Table 2. As shown in Table 2, the major isotopes taken into consideration are ${ }^{31} \mathrm{Si}$ and ${ }^{56} \mathrm{Mn}$ if the activity measurement is made at the times betweeen 1 and $10 \mathrm{hr}$ after irradiation, because the radioisotopes having short half-life decay within a short period of time and the radioisotopes of long half-life are hardly produced in this case. Moreover, the manganese in silicon can easily be separated during the extraction process of $\mathrm{SiO}_{2}$, and therefore, the radioactivity of the material extracted may be expected to be the radioactive silicon itself.

\section{Iron Samples and Analyses}

Samples for the measurement of radioactivity were taken out from the melt by suction with a silica tube of $0.5 \mathrm{~cm}$ i.d. at the times previously determined. In order to ensure the uniform mixing of radioactive silicon added, the melt was allowed to stand for at least $40 \mathrm{sec}$ before sampling. Samples obtained were then subjected to chemical analyses. Total oxygen was determined by the vacuum fusion method. On the other hand, contents of silicon and $\mathrm{SiO}_{2}$ were determined by the spectrophotometric method and the nitric acid solution method, respectively.

\section{Measurement of Radioactivity}

About $5 \mathrm{~g}$ of sample was dissolved in nitric acid and then $\mathrm{SiO}_{2}$ was separated from the solution as a residue by filtration. The filter paper carring $\mathrm{SiO}_{2}$ was carefully dried and then placed under an end window type GM counter for the measurement of radioactivity.

Since the measurements of the radioactivity should be made as precise as possible, count rate of the radioactivity was carefully controlled to be at least $1000 \mathrm{cpm}$ for all samples. Owing to the short halflife of ${ }^{31} \mathrm{Si}$, all measurements of radioactivity were made within $8 \mathrm{hr}$ after the irradiation of silicon. From the radioactivity of $\mathrm{SiO}_{2}$ obtained, it was found that the content of dissolved oxygen can be accurately determined up to $0.0001 \%$.

Due to the fact that absorptions of $\beta$-ray of ${ }^{31} \mathrm{Si}$ by the specimen itself, air, and the mica window of GM counter were insignificant, correction of the count rates was only made for the decay of ${ }^{31} \mathrm{Si}$ during the time elapsed from the time of irraditation. In order to check the relative strength of $a_{\mathrm{A}}$ and $a_{\mathrm{B}}$, a small piece of silica, used as a standard specimen, was activated at the same time with silicon for each radiation. In each experimental run, at least five to eight samples were taken out from the melt for the radioactivity measurement and the average value for these samples was taken as the radioactivity of the melt. Count rates were ranging from 1000 to $10000 \mathrm{cpm}$ in the current investigation.

\section{Experimental Results and Discussions}

\section{Change in Composition of Oxide Inclusions}

Compositions of oxide inclusions formed by the addition of $0.5 \%$ silicon were determined chemically by the use of the iodine methanol method which is considered as the most reliable method in isolating FeO from iron (Fig. 2). As shown in Fig. 2, it was found that a small amount of oxygen can exist as the form of $\mathrm{FeO}$ for a short period of time, about $1 \mathrm{~min}$, after the addition of silicon. However, the most of oxygen exists in the form of $\mathrm{SiO}_{2}$. Oxygen in the form of $\mathrm{FeO}$ remains nearly constant after the initial period of deoxidation and its average value is about $0.0008 \%$.

Table 2. Amounts of radioisotopes produced in $1 \mathrm{~g}$ of silicon: irradiated for $1 \mathrm{hr}$ with a thermal neutron flux of $1.0 \times 10^{11} \mathrm{n} / \mathrm{cm}^{2} \mathrm{sec}$

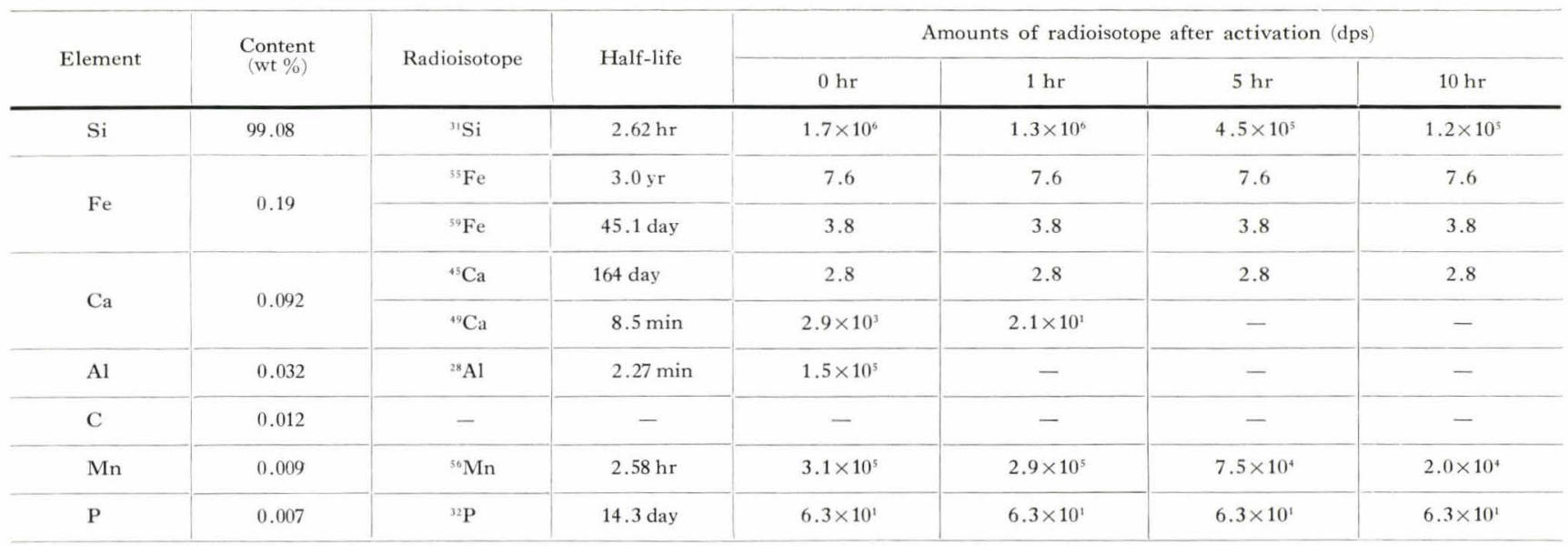




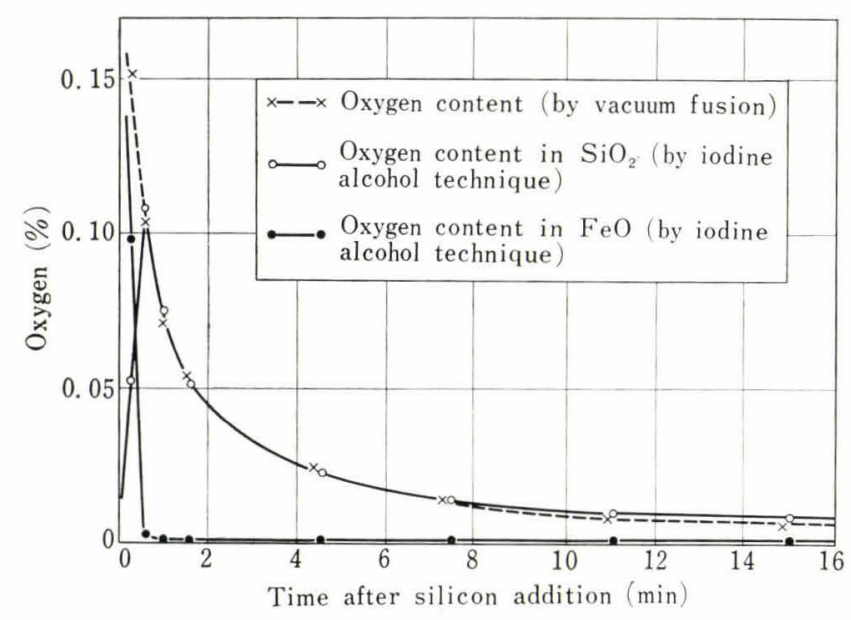

Fig. 2. Changes in the compositions of deoxidation products with time

\section{Reliability of Isolation of $\mathrm{SiO}_{2}$ by the Nitric Acid Solution Method}

Since the half-life of ${ }^{31} \mathrm{Si}$ is relatively short, $\mathrm{SiO}_{2}$ in iron should be separated in a time as short as possible. Therefore, the nitric acid solution method was used because it is considered as the best method for the isolation of $\mathrm{SiO}_{2}$ within a short time. In order to know whether the complete isolation of $\mathrm{SiO}_{2}$ is possible or not by the use of this method, the oxygen content calculated from the amount of $\mathrm{SiO}_{2}$ extracted was compared with the values determined by vacuum fusion analysis. Samples used were taken out from the melt kept for at least $40 \mathrm{sec}$ for mixing after the silicon addition. As shown in Fig. 3, these values agreed well within the experimental errors.

In order to check the loss of $\mathrm{SiO}_{2}$ inclusions, isolated $\mathrm{SiO}_{2}$ was immersed in nitric acid solution for over $24 \mathrm{hr}$. Among $\mathrm{SiO}_{2}$ inclusions many small particles whose diameters were less than $1 \mu$ were observed under the electron microscope. Existence of these small particles may indicate that $\mathrm{SiO}_{2}$ in solid iron can successfully be isolated by the nitric acid solution method, without any significant loss.

\section{Changes in Dissolved and Total Oxygen Contents}

Variation of the contents of dissolved oxygen by the addition of silicon were studied by changing the heating time of experiment-B. The results obtained are shown in Table 3.

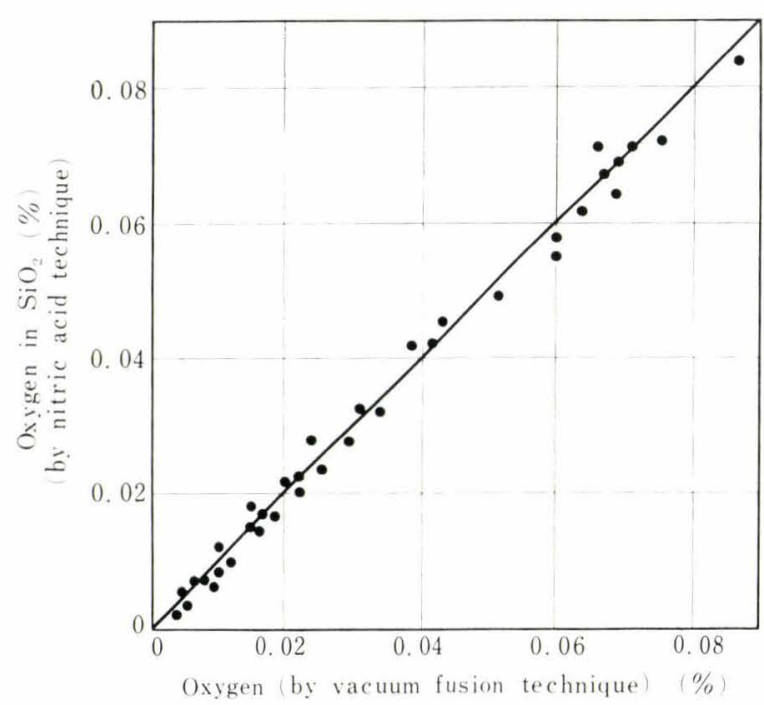

Fig. 3. Relation between the oxygen content in $\mathrm{SiO}_{2}$ extracted by the nitric acid solution technique and the oxygen content by the vacuum fusion technique

Initial oxygen contents of the melts are not the same, because partial pressure of oxygen in argon atmosphere was not kept constant in each heat of experiments. Values of metallic silicon content in Table 3 were obtained from the difference between the amount of added silicon and that of silicon in the form of $\mathrm{SiO}_{2}$ produced by the time $t_{2}$. The latter was calculated from the difference of the initial and the dissolved oxygen contents at the time $t_{2}$. Oxygen contents calculated from the equilibrium data of Si-O system $^{7)^{-9)}}$ are also listed in Table 3.

In order to know the change in the total oxygen content, experiments were also made under the same conditions previously described (Fig. 4). As shown in Fig. 4, the total oxygen content decreases with time and then becomes nearly constant in $8-10 \mathrm{~min}$ after the addition of silicon. On the other hand, the dissolved oxygen content decreases very sharply within $1 \mathrm{~min}$ after the addition of silicon and then continues to decrease very slowly. These results show that the chemical reaction $\underline{\mathrm{Si}}+2 \underline{\mathrm{O}}=\mathrm{SiO}_{2}$ is almost completed within $1 \mathrm{~min}$ after the addition of silicon, and the decreasing rate of the total oxygen content is mainly controlled by the rate of removal of the deoxidation products. Reliability of the present method may well be justified by the experimental

Table 3. Results of experiments

\begin{tabular}{|c|c|c|c|c|c|c|c|}
\hline & Heat No. & 1 & 2 & 3 & 4 & 5 & 6 \\
\hline \multicolumn{2}{|c|}{ Minutes after silicon addition $\left[t_{2}\right]$} & 0.25 & 0.50 & 1.20 & 3.00 & 6.50 & 12.00 \\
\hline \multicolumn{2}{|c|}{ Initial oxygen content $\left[\underline{\mathrm{O}_{1}}\right](\%)$} & 0.113 & 0.106 & 0.104 & 0.139 & 0.138 & 0.138 \\
\hline \multicolumn{2}{|c|}{ Metallic silicon content (\%) } & - & - & 0.402 & 0.385 & 0.428 & 0.396 \\
\hline \multicolumn{2}{|c|}{$\begin{array}{l}\text { Dissolved oxygen content determined in the present } \\
\text { work }\left[\underline{\mathrm{O}}_{2}\right](\%)\end{array}$} & 0.0378 & 0.0210 & 0.0104 & 0.0097 & 0.0095 & 0.0062 \\
\hline \multirow{3}{*}{$\begin{array}{l}\text { Calculated oxygen } \\
(\%)\end{array}$} & Gokcen and Chipman ${ }^{7)}$ & - & - & 0.0084 & 0.0085 & 0.0081 & 0.0084 \\
\hline & Hilty and $\mathrm{Craft}^{8)}$ & - & - & 0.0086 & 0.0088 & 0.0083 & 0.0086 \\
\hline & Matoba, Gunji and Kuwana & - & - & 0.0076 & 0.0077 & 0.0073 & 0.0076 \\
\hline
\end{tabular}




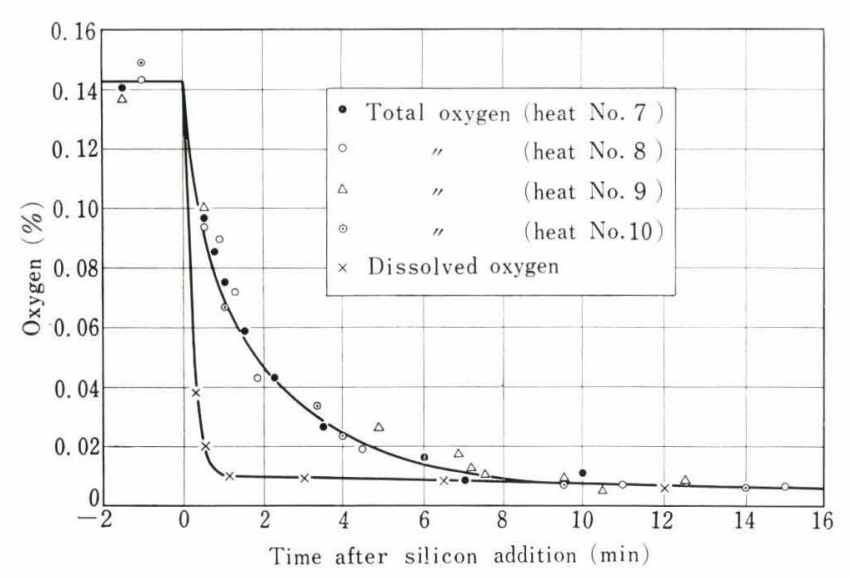

Fig. 4. Changes in the contents of total oxygen by the vacuum fusion technique and the dissolved oxygen in the present work at $1600^{\circ} \mathrm{C}$

evidence obtained, i.e. the content of dissolved oxygen agreed well with the content of total oxygen for the experiment at $12 \mathrm{~min}$. All of the inclusions found in iron samples were silica of typical type and the particle diameter is less than $10 \mu$ for the most.

In Fig. 4, the difference of total and dissolved oxygen contents in the process of deoxidation corresponds to the amount of oxygen combined as primary deoxidation products in the melt, and it is re-plotted in Fig. 5. From the comparison of the curve for $\mathrm{FeO}$ in Fig. 2 and the curve for primary deoxidation products shown in Fig. 5, it can be concluded that the primary deoxidation products are consisted of $\mathrm{SiO}_{2}$ and that there is no inclusion containing $\mathrm{FeO}$ when the melt is kept for at least 1 min or more after the addition of silicon. Due to the fact mentioned above, a small amount of $\mathrm{FeO}$ found in the final products may be considered as the product formed during the process of cooling and freezing.

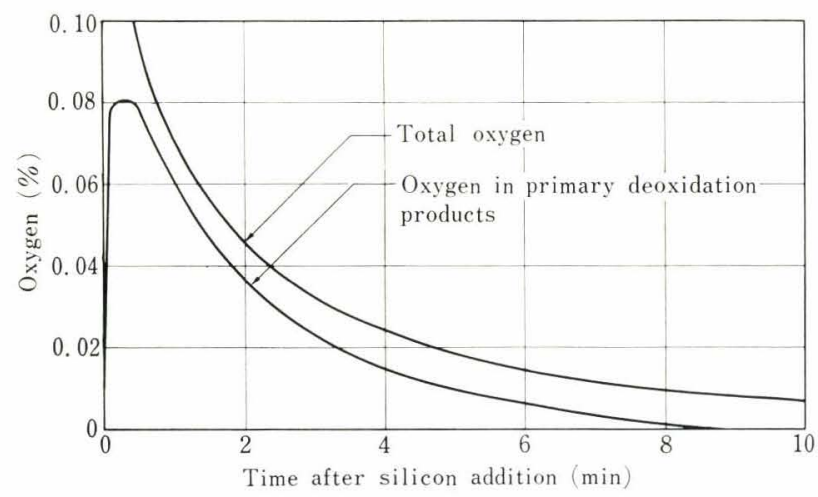

Fig. 5. Changes in the amounts of oxygen in the primary deoxidation products and the total oxygen content

In the present method, it is possible to assume that the major part of the dissolved oxygen combines with silicon to form $\mathrm{SiO}_{2}$ during the period of cooling and freezing; however, only a minor part of the oxygen combines with iron in the form of $\mathrm{FeO}$ as shown in Fig. 2. When the rate of the dissolved oxygen which combines with silicon during the period of cooling and freezing is designated as $\alpha$, this factor depends approximately on the content of metallic silicon in the melt. The value $\alpha$ can, therefore, be calculated from the amount of $\mathrm{FeO}$ in Fig. 2 and the amount of the dissolved oxygen in Fig. 4. Results thus obtained are shown in Fig. 6 as a function of the content of metallic silicon. For convenience, metallic silicon in solid iron is used instead of the value of the melt. As shown in Fig. 6, the value of $\alpha$ is approximately constant, i.e. 0.9 in the range of 0.1 to $0.4 \%$ of metallic silicon.

When the contents of metallic silicon in solid iron and in the melt are designated as $[\% \underline{\mathrm{Si}}]_{\mathrm{S}}$ and $[\% \underline{\mathrm{Si}}]_{\mathrm{L}}$ respectively, these are related as

$$
[\% \underline{\mathrm{Si}}]_{\mathrm{L}}=[\% \underline{\mathrm{Si}}]_{\mathrm{S}}+(28.09 / 32) \alpha[\% \underline{\mathrm{O}}]
$$

The content of metallic silicon in solid iron can be determined by chemical analysis, and therefore, the content of metallic silicon in the melt can easily be calculated from the equation mentioned above.

Fig. 7 (a) shows the change in the content of metallic silicon in the melt calculated by Eq. (9). According to the results obtained, the silicon added is dissolved uniformly in the melt within $1 \mathrm{~min}$. The contents of dissolved oxygen determined in the present work are shown in Fig. 7 (b) in comparison with the values calculated from the data presented by Gokcen

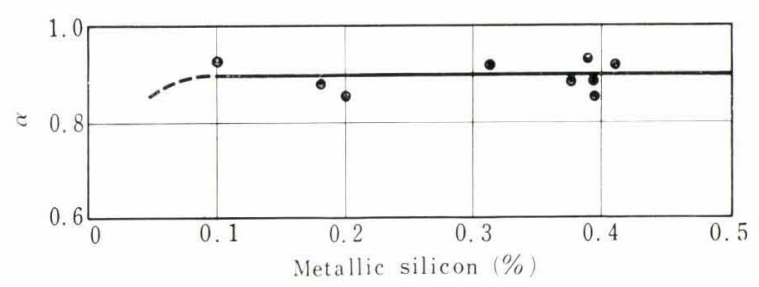

Fig. 6. Relation between the metallic silicon content and the ratio of the dissolved oxygen content $(\alpha)$ which combines with silicon during cooling and freezing

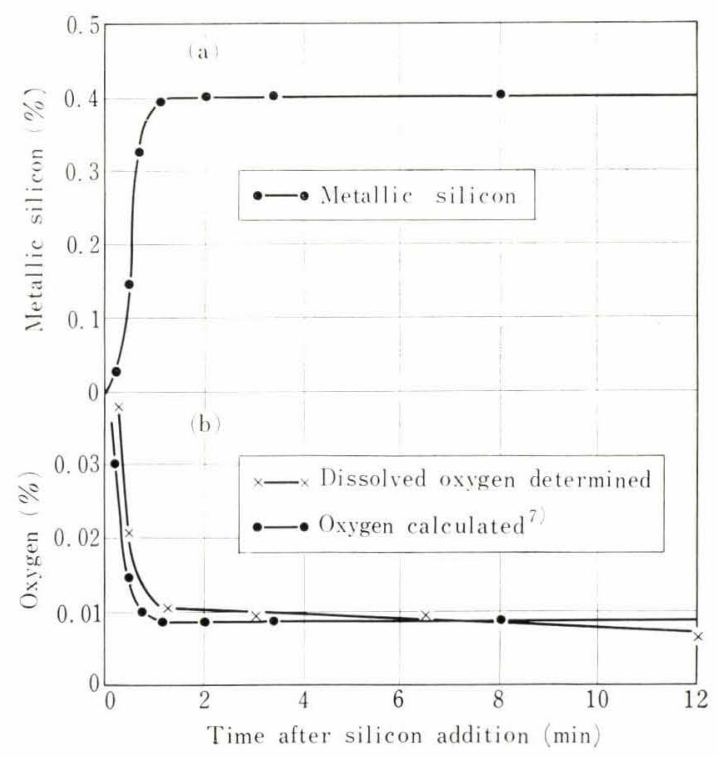

Fig. 7. Change in the content of metallic silicon with time (a), and comparison of the oxygen content calculated from $\mathrm{Si}-\mathrm{O}$ equilibrium with the observed value at $1600^{\circ} \mathrm{C}(\mathrm{b})$. 
and Chipman ${ }^{\text {7) }}$ by assuming that the system is in equilibrium state. Since these values are agreed well in each stage, it may be considered that the dissolved oxygen is in equilibrium state with metallic silicon in each stage of deoxidation. Therefore, it is possible to assume that the rate of decrease in the content of dissolved oxygen is mainly due to the rate of increase in the content of metallic silicon at the initial stage. However, it is not clearly understood why the dissolved oxygen decreases continuously even after $1 \mathrm{~min}$ when the content of metallic silicon is kept constant. The decrease of activity of $\mathrm{SiO}_{2}$ in the slag may partly account for the fact because magnesia crucibles were used for melting in the present work.

Chemical reactions taking places during iron and steel making processes have been considered to be completed within a very short time because of very high temperature, i.e. $1400^{\circ}$ to $1700^{\circ} \mathrm{C}$. The experimental evidence has not been obtained for many years. In recent studies ${ }^{10)-12)}$ on the kinetics of deoxidation it is assumed that the chemical reaction of deoxidation proceeds very rapidly. On the other hand, Sims ${ }^{13)}$ has pointed out that the reaction may proceed not so rapidly, and Senda ${ }^{14}$ ) has reported that in certain cases metallic elements are not in equilibrium with dissolved oxygen.

For the case of silicon, Fulton and Chipman ${ }^{15}$ studied the reduction of $\mathrm{SiO}_{2}$ by carbon in iron and concluded that the chemical reaction is the rate controlling step in this process because of its large activation energy. For the same reaction, however, Rawling and Elliott ${ }^{16)}$ reported that transfer of oxygen in boundary layer of iron at the slag-metal interface is the rate controlling step below $1600^{\circ} \mathrm{C}$. King ${ }^{17)}$ proposed that the phase boundary reaction

$$
\underline{\mathrm{Si}}=\mathrm{Si}^{4+}+4 \mathrm{e}^{-}
$$

may be the rate controlling step for the inverse reaction, that is, the oxidation of silicon by slag. Sano, Shiomi and Matsushita ${ }^{18)}$ also studied the deoxidation mechanism from the same point of view. On the other hand, Ward ${ }^{19)}$ states that the rate of oxidation of silicon in steel by slag containing iron oxide is relatively fast as compared with the rate of reduction of silica in slag.

In the present study, the amount of dissolved oxygen in the process of deoxidation agreed well with the value predicted by the $\mathrm{Si}-\mathrm{O}$ equilibrium as shown in Fig. 7. It may indicate that the time required for completion of the chemical reaction is negligibly small, that is, the rate of deoxidation by silicon is fast. Rapid decrease in the content of dissolved oxygen in the process of deoxidation is also found by Matsushita and Gotō $^{-3)}$ in the electro-chemical experiment.

\section{Discussion of the Assumptions Made in the Present Study}

Among the assumptions made in this study, Assumption (1) is the fundamental requirement in the tracer technique. This assumption may be well satisfied for the case of silicon, since the isotope effect is negligible. Assumption (2) is not well satisfied as shown in Fig. 7 (a); however, it is not so serious except for the cases of runs Nos. 1 and 2, since the samples used for $\mathrm{SiO}_{2}$ extraction were taken out after ${ }^{31} \mathrm{Si}$ was mixed uniformly.

Assumption (3) was justified by the results of the following experiment. Small amount of radioactive silicon was added to the melt at the time 2 min after the inactive silicon had been added for deoxidation, and then several samples were taken out from the melt at scheduled times. The result indicates that the radioactivity of $\mathrm{SiO}_{2}$ extracted from $1 \mathrm{~g}$ of each iron sample remained constant as shown in Fig. 8 . The amount of the total oxygen 2 min after the addition of silicon was found to be five times larger than the equilibrium value (Fig. 4). If the exchange of silicon atoms takes place between metal and oxide, the radioactivity of $\mathrm{SiO}_{2}$ should increase in the initial stage and then decrease to a certain value due to the removal of $\mathrm{SiO}_{2}$ particles. However, the observed values of the radioactivity are nearly constant. It is therefore possible to assume that there is no exchange of silicon between metal phase and oxide phase. This may be attributed to the fact that $\mathrm{SiO}_{2}$ is in the solid state having the strong bond between silicon and oxygen at $1600^{\circ} \mathrm{C}$. According to Derge and Birchenall ${ }^{20)}$, the exchange of iron has been observed experimentally between the iron silicate slag and the metal, therefore, the exchange of atoms may be seen in the process of deoxidation when the other elements than silicon are used as the deoxidizer.

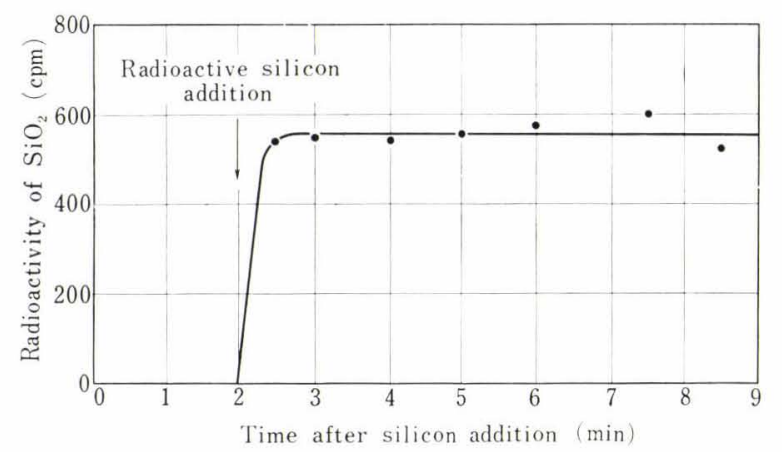

Fig. 8. Radioactivity of $\mathrm{SiO}_{2}$ in the melt as the function of time. $\mathrm{SiO}_{2}$ was extracted from $1 \mathrm{~g}$ iron at various times after addition of radioactive silicon in $2 \mathrm{~min}$ after deoxidation and its radioactivity was measured.

Assumption (4) is nearly fulfilled except the cases of runs Nos. 1 and 2. Since the equilibrium oxygen decreases by only $0.001 \%$ when extra $0.1 \%$ silicon is added to the melt, which is containing $0.4 \%$ silicon originally, no significant effect may be expected on the decrease of oxygen content by the addition of small amount of radioactive silicon in the process of deoxidation.

Assumption (5) is not well satisfied in a strict sense as shown in Fig. 2, because some portion of the dissolved oxygen combines with iron in the form of $\mathrm{FeO}$ 
during the period of cooling and freezing. Since the amount of oxygen combined with iron is not included in the amount of oxygen determined in the present work, the present values are smaller than the true amount of dissolved oxygen by about $10 \%$ except for the cases of runs Nos. 1 and 2. The difference between these values is still greater for latter cases.

All samples are taken out from the melt at times more than $40 \mathrm{sec}$ after the addition of silicon, Assumption (6) may be well satisfied as already discussed in Fig. 3.

\section{Content of Dissolved Oxygen Determined}

Since all assumptions are reasonable to apply for the experiments of Nos. 3-6, no correction is necessary for the determined values of the dissolved oxygen content. However, Assumptions (2), (4) and (5) are not sufficiently satisfied for the runs Nos. 1 and 2 and the determined values are all under-estimated. Among these three assumptions, most serious consideration should be paid for Assumption (4). However, the true amounts of the dissolved oxygen for the runs Nos. 1 and 2 are expected to be only a little larger than that determined in the present work. The results suggest that the error due to Assumption (4) is not so significant. Since six experimental runs were carried out in the same way (Table 3), results obtained in the present study may well be used in determining the change in the content of dissolved oxygen during the silicon deoxidation process.

Similar results may be expected for the change of the dissolved oxygen during the deoxidation process when the other elements than silicon are used. The present technique was applied by Miyashita ${ }^{21)}$ for the study of deoxidation with manganese, but the results reported are not so satisfactory because of the exchange of manganese or iron between the metal and oxide phases. It seemed likely, even in this case, that the dissolved oxygen content at each stage of deoxidation is in agreement with the value predicted by the Mn-O equilibrium.

\section{Discussion on the Technique Used for the Determination of the Dissolved Oxygen Content}

The present technique for the determination of the dissolved oxygen content is based on the assumptions that the oxygen originally present in the melt and the silicon added to the melt are the reacting species for the deoxidation, and that silicon dissolves completely in the melt without any loss. Attentions have been paid to satisfy the requirements for the assumptions made in the present work. However, in order to generalize this technique, the specific radioactivity of metallic silicon in samples should be measured and then the dissolved oxygen content $\underline{\mathrm{O}}_{2}$ should be calculated by the following equation.

$$
\underline{\mathrm{O}}_{2}=(100)^{2} \frac{32}{28.09} \frac{1}{3.7 \times 10^{7}} \frac{1}{\eta} \frac{I}{a},
$$

where $\eta$ is the efficiency (\%) of GM counter for ${ }^{31} \mathrm{Si}$, $I$ is the count rate (cps) of $\mathrm{SiO}_{2}$ extracted from $1 \mathrm{~g}$ of iron sample, and $a$ is the specific activity $(\mathrm{mc} / \mathrm{g}$ ) of metallic silicon in iron sample.

Using Eq. (10), the amount of the dissolved oxygen in certain time after the addition of silicon can be determined by making only one experiment. In this case, the method will be more generalized, since it is independent of the restrictions which Eq. (3) requires. Although the present study is based on Eq. (8) derived from Eq. (3), some trials have been made to determine the content of dissolved oxygen from Eq. (10). Results thus obtained agreed well with those listed in the paper.

\section{Conclusions}

Radioactive tracer method is developed for the direct determination of the dissolved oxygen content in melt containing oxide inclusions in it. Using this method, the change in the content of dissolved oxygen in the melt during the process of silicon deoxidation is clarified. The results obtained are as follows :

(1) The amount of the dissolved oxygen decreases very rapidly within $1 \mathrm{~min}$ after the addition of silicon and then decreases very slowly. It is confirmed that the time required for the chemical reaction $\underline{\mathrm{Si}}+2 \underline{\mathrm{O}}=\mathrm{SiO}_{2}\left(\underline{\mathrm{Si}}=\mathrm{Si}^{4+}+4 \mathrm{e}^{-}\right)$is negligible since the observed oxygen content at each stage of deoxidation was found in agreement with the value predicted by equilibrium relation with silicon. This fact also indicates that the decreasing rate of the dissolved oxygen can be estimated from the increasing rate of the metallic silicon in melt.

(2) Comparison of the changes of the dissolved and the total oxygen shows that the rate of decrease of the total oxygen is determined by the rate of removal of the deoxidation products.

(3) The primary deoxidation products show that these are $\mathrm{SiO}_{2}$ only, and the existence of $\mathrm{FeO}$ is not observed by analysis. Thus a small amount of $\mathrm{FeO}$ found in the final products should be the product of the processes of cooling and freezing. When silicon content is in the range of 0.1 to $0.4 \%$, about $90 \%$ of the dissolved oxygen combines with silicon during cooling and freezing.

(4) The exchange of silicon between the metal and oxide particles does not take place.

\section{Acknowledgements}

The author wishes to thank Dr. Kōki Gunji, Chief of Steel-Making Laboratory, National Research Institute for Metals, for many helpful discussions and suggestions during this work.

\section{REFERENCES}

1) M. Ohtani and K. Sanbongi: Tetsu-to-Hagané, 49 (1963), 22.

2) K. Sanbongi, M. Ohtani, Y. Ohmori and H. Inoue: Tetsuto-Hagané, 50 (1964), 1823.

3) Y. Matsushita and K. Gotō: Trans. Iron Steel Inst. (Japan), 6 (1966), 131.

4) В.Л. Лузгин, А.Ф. Вишкарев and В.И. Явойский : Изв. ВУЗ. Черная Металлургия, (1963), No. 5, 44; No. 9, 50 .

5) W. A. Fischer and W. Ackermann: Arch. Eisenhüttenw., 36 
(1965), 643 and 695.

6) Y. Miyashita: Tetsu-to-Hagané, 51 (1965), 788 and 790.

7) N. A. Gokcen and J. Chipman: Trans. Metal. Soc. AIME, 192 (1952), 171

8) D. C. Hilty and W. Crafts: Trans. Metal. Soc. AIME, 188 (1950), 425.

9) S. Matoba, K. Gunji and T. Kuwana: Trans. Nat. Res. Inst. Metals (Japan), 3 (1961), 81.

10) W. A. Fischer and M. Wahlster: Arch. Eisenhüttenw., 28 (1957), 601.

11) E. Plöckinger and M. Wahlster: Stahl u. Eisen, 80 (1960), 659.

12) T. Kawawa, M. Ohkubo, Y. Sasajima and K. Gunji: Tetsuto-Hagané, 51 (1965), 774.

13) C. E. Sims: Trans. Metal. Soc. AIME, 215 (1959), 367.
14) K. Senda: Tetsu-to-Hagané, 51 (1965), 185

15) J. C. Fulton and J. Chipman: Trans. Metal. Soc. AIME, 215 (1959), 888

16) J. R. Rawling and J. F. Elliott: Trans. Metal. Soc. AIME, 233 (1965), 1539.

17) C. E. Sims ed.: Electric Furnace Steelmaking, Vol. II, (1963), 347, [John Wiley \& Sons].

18) N. Sano, S. Shiomi and Y. Matsushita: Tetsu-to-Hagané, 51 (1965), 19.

19) R. G. Ward: An Introduction to the Physical Chemistry of Iron and Steel Making, (1962), 174, [Edward Arnold].

20) G. Derge and C. E. Birchenall: Trans. Metal. Soc. AIME, 197 (1953), 1648.

21) Y. Miyashita: Tetsu-to-Hagané, 52 (1966), 1049. 